\title{
Neuropsychological prediction of conversion to dementia from questionable dementia: statistically significant but not yet clinically useful
}

\author{
J Tian, R S Bucks, J Haworth, G Wilcock
}

See Editorial Commentary P 413

See end of article for authors' affiliations

....................

Correspondence to: Professor G Wilcock, Department of Care of the Elderly, Frenchay Hospital, Bristol BS16 1LE, UK; Gordon.Wilcock@bris.ac.uk

Received 13 March 2002 Accepted in revised form 21 November 2002

\begin{abstract}
Background: Verbal memory impairment, one of the earliest signs of Alzheimer's disease (AD), may help identify people with cognitive impairment, insufficient for a diagnosis of dementia (questionable dementia: $Q D$ ), at risk of developing AD. Other cognitive parameters have been found that may indicate which people with QD will go on to develop dementia. Nevertheless, some researchers have reported only partial success in differentiating between mild $A D$ and age related cognitive impairment. Objectives: To discover if there are early, pre-clinical cognitive markers that could help identify patients attending our memory clinic who were at risk of developing dementia.

Methods: Multidisciplinary assessment of a consecutive sample of 195 patients with QD seen in a National Health Service hospital outpatient clinic; 135 seen for a mean follow up of 24.5 months.

Results: Conversion rate to dementia was $27.4 \%$ (37 of 135). A diagnosis of probable or possible AD was made in $15.6 \%$ (21 of 135) of cases. Despite statistically significant differences in some cognitive tasks between those who did and those who did not go on to dement, Cox regression analyses failed to improve prediction rates markedly above base rates and were unstable.

Conclusion: A large number of studies claim good prediction of conversion to dementia using cognitive test scores. Although this study produced similarly good sensitivity and specificity values, proper consideration of the statistical analyses and their clinical significance suggested that these prediction methods are currently too imprecise for clinical use. Use of cognitive indicators combined with neuroradiological, neuropathological, and genetic factors for predicting conversion to dementia might prove more reliable but may be beyond the scope of many geriatric services.
\end{abstract}

$\mathrm{T}$ he potential to identify people at risk of developing dementia, particularly Alzheimer's disease (AD), has important implications for diagnosis and treatment of early disease, ${ }^{1}$ although whether mild cognitive impairment represents early stage $\mathrm{AD}$ remains controversial..$^{2-5}$ There is considerable evidence to support the concept of a preclinical phase in $\mathrm{AD} .{ }^{4-8}$ Community studies have reported between $17 \%$ and $30 \%$ of people over the age of 65 years have cognitive impairment without meeting diagnostic criteria for dementia, ${ }^{10}$ many of whom meet diagnostic criteria for dementia after follow up, ${ }^{2}$ with the proportion converting increasing with increasing length of follow up. ${ }^{11}{ }^{12}$ It has also been suggested that older people convert from a diagnosis of questionable dementia (QD) to dementia more rapidly than those who are younger. ${ }^{7}$ Finally, both the patients who subsequently dement and their informants seem to be aware of declines in function up to five years before diagnosis. ${ }^{13}$ The difficulty, however, is in determining which of these people is in the early stages of a dementing disorder and which is suffering non-progressive cognitive impairment related to some other cause.

A number of longitudinal studies has attempted to predict who will convert to dementia using neuropsychological parameters (see Collie and Maruff for a review). Verbal and visuospatial memory impairment have been reported both as one of the earliest signs ${ }^{14-17}$ and are associated with increased risk of developing dementia. ${ }^{818-22}$ Other cognitive parameters include tests of naming, abstraction, and verbal fluency, ${ }^{2} 192023-26$ and visuospatial and executive functioning. ${ }^{26}$ Less consistent is the relation between measures of attention or strategic control and final diagnosis, with some studies finding significant differences ${ }^{19} 22^{28}$ and others not. ${ }^{29}$ In contrast, other researchers have reported little or no success in predicting the development of dementia ${ }^{13}$ or in differentiating between mild $\mathrm{AD}$ and age related cognitive impairment. ${ }^{30} 31$

A number of published studies have attempted to draw distinctions between people with QD who will and will not dement. These can be divided into those that have recruited

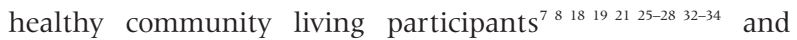
those that have recruited people with minimal cognitive impairment. ${ }^{25}{ }^{175-38}$ Percentage correct prediction values for these studies vary greatly: sensitivity $50.0 \%-91.4 \%$, specificity $5.9 \%-99.0 \%$ for community studies; sensitivity $74.0 \%-83.3 \%$, specificity $76.9 \%-94.0 \%$ for minimal cognitive impairment studies. Criteria used to diagnose people in the minimal cognitive impairment studies are also diverse. Some have included all people who were not normal but not yet demented (QD, for example, Devanand et $a^{2}$ ), others recruited people with age associated memory impairment $\left(\mathrm{AAMI}^{39}\right.$; for example, Hanninen $e t a l^{17}$ ). Thus, differences in the people recruited for these studies have led to large differences in rates for conversion to dementia (9.1\% to $41.9 \%)$ see also Ritchie and Touchon ${ }^{40}$ and Collie and Maruff. ${ }^{41}$

In addition, there is the issue of censored cases; that is people who are lost to the study before a diagnosis is made. This leads to a risk of bias if any of the explanatory variables are, by chance, correlated with time to follow up or diagnosis. Cox regression (survival analysis) is a method for modelling time to event data that can account for censored cases. Only three studies have used Cox regression, and all of these were community studies. ${ }^{81821}$

Abbreviations: $A D$, Alzheimer's disease; $Q D$, questionable dementia 


\begin{tabular}{llll} 
Table 1 Descriptive statistics & & \\
\hline $\mathrm{n}=129$ Mean (SD), range & Developing dementia (D) $\mathrm{n}=37$ & Stable QD $\mathrm{n}=92$ & $\mathrm{p}$ Value \\
\hline Men & $17(46 \%)$ & $51(55 \%)$ & 0.616 \\
Women & $20(54 \%)$ & $41(45 \%)$ & 0.016 \\
History of cognitive impairment (months) & $19.4(13.1), 2-54$ & $32.0(30.5), 3-156$ & 0.083 \\
Time to diagnosis or survival (months)* & $25.3(19.4), 7.2-81.2$ & $19.7(17.0), 4.8-90.8$ & 0.000 \\
Time to last visit (months) & $36.0(21.3), 7.7-95.7$ & $19.7(17.0), 4.8-90.8$ & 0.020 \\
Age (y) & $73.2(8.5), 52-88$ & $68.7(10.2), 46-88$ & 0.848 \\
Education (y) & $10.8(3.0), 5-21$ & $10.9(2.6), 6-23$ & 0.701 \\
Stockton dependency rating $\dagger$ & $3.4(3.2), 0-12$ & $3.2(3.3), 0-16$ & 0.830 \\
Hachinski ischaemia scoreł & $3.1(2.4), 1-10$ & $3.2(2.2), 0-13$ & 0.913 \\
Cornell depression scale§ & $4.2(3.9), 0-14$ & $4.3(3.7), 0-17$ & 0.000 \\
MMSE & $23.0(3.2), 15-30$ & $25.2(3.2), 15-30$ & 0.544 \\
NART Predicted IQ 1 & $106.6(13.5), 77-129$ & $108.1(13.0), 77-129$ &
\end{tabular}

Values are: *time to survival for stable $Q D$ patients is the same as time to last visit; $\lceil n$ of $Q D=89$; $¥ n$ of $Q D=91 ; \S n$ of $Q D=89$; 9 no of $D=36, n$ of $\mathrm{QD}=89$.

To be of practical utility, we need a method of accurately predicting outcome for the types of patients attending an outpatient assessment clinic. That is, people who are neither quite normal, nor clearly demented (that is, QD). Thus, this study aimed to determine whether the predictive results offered by Devanand and colleagues were replicable in a UK sample using different neuropsychological tests. As such, it was a test of the general principle of predicting subsequent conversion to dementia from neuropsychological measures. However, we made two key changes to the method in that we used Cox regression and varied the data type and models used to determine how stable the predictive solutions might be.

\section{METHOD}

\section{Participants}

Participants were 568 consecutive new patients attending the Bristol Memory Disorders Clinic between 7 June 1993 to 28 August 1997. During this period 195 (34.3\%) had QD, 370 $(65.0 \%)$ were diagnosed with a dementia, and three $(0.5 \%)$ were found to have no cognitive impairment at all. Of the 195 QD patients, 135 (69.2\%) were seen for at least one follow up visit.

Patients were referred to the Bristol Memory Disorders Clinic (BMDC) by their GP or other healthcare professional. Each patient underwent medical, psychiatric, and psychological screening to exclude any other treatable disease. Particular attention was paid to presenting symptoms, onset (sudden or insidious), progression (static, stepwise, or gradual), and presence of memory and other cognitive problems, as well as affective or behavioural difficulties. Past medical history was also evaluated, emphasising conditions that might be associated with cognitive impairment, medications, and substance misuse. Family history of depression and organic or neurological disease was also noted. A depression rating scale was used (Cornell Scale for Depression in Dementia). ${ }^{42}$ Patients were referred to a psychiatrist if there was any clinical suspicion of affective or psychotic illness or if they scored above the cut off on the depression rating scale.

Behavioural and functional deficits were measured in interview with a knowledgeable collateral source (generally a spouse or adult child) using the Stockton Geriatric Rating Scale. ${ }^{43}$ The standardised Hachinski Ischaemic Scale ${ }^{44} 45$ was administered. A comprehensive physical examination was undertaken including neurological examination. Laboratory blood testing, CT brain scans, and where clinically indicated single photon emission computed tomography or magnetic resonance imaging were also carried out.

The neuropsychological assessment used in the BMDC was designed and validated specifically for the clinic. ${ }^{46}$ The assessment included measures of higher order cognitive function assessing short-term and working memory (Digit Span, forwards and backwards), abstract thinking (Similarities), and general non-verbal problem solving (Picture Completion) all Wechsler Adult Intelligence Scale-Revised (WAIS- $\mathrm{R}^{47}$ ), measures of episodic memory assessing immediate and delayed story recall (Adult Memory and Information Processing Battery $\left.^{48}\right)$, list recall, verbal learning, and verbal recognition (Hopkins Verbal Learning Test: HVLT $^{49}$ ), and visual recognition (Middlesex Elderly Assessment of Mental State: $\left.M^{M E A M S}{ }^{50}\right)$. Other tests assessed language expression, reception, and executive function using the Frenchay Aphasia Screening Test, ${ }^{51}$ letter fluency, ${ }^{52}$ and Weigl's Colour Form Sorting Test $^{53}$ and measures of visuospatial function (Cube analysis, Visual Object Space Perception Battery ${ }^{54}$ ) and psychomotor speed (Digit copying ${ }^{55}$ ).

Each patient's assessments were discussed in a multidisciplinary case conference by trained clinicians. The diagnosis was based on a history of cognitive impairment relative to the patient's premorbid abilities. Impairment in any cognitive function was defined as performance 1.5 or more SD below expected level of functioning using age adjusted means. For $\mathrm{AD}$, this history was of gradual onset and progressive course. Diagnosis of dementia was made according to the Diagnostic and Statistical Manual of Mental Disorders-Revised IV Edition. ${ }^{56}$ A diagnosis of probable $\mathrm{AD}$ was made according to the NINCDS-ADRDA criteria. ${ }^{57} \mathrm{~A}$ diagnosis of QD was made if a patient was (a) experiencing memory impairment that affected their social or occupational functioning but without other cognitive impairment, or (b) experiencing cognitive impairment in one or more areas of functioning but this impairment did not result in significant change in social or occupational functioning. Thus, a diagnosis of QD indicated that there was objective evidence of cognitive impairment but that these impairments did not satisfy the criteria for dementia. The outcome measure was the final diagnosis at follow up.

One hundred and thirty five participants were followed up for 4.8 to 95.7 months (mean 24.5, SD 19.7, range 1-7 follow up visits, mode 1 , median 2 ). At final follow up their diagnoses were reviewed, at which time $37(27.4 \%)$ had gone on to develop dementia and $92(68.1 \%)$ continued to suffer QD, additionally, six $(4.4 \%)$ had recovered from all cognitive deficits and were deemed to be normal. Table 1 gives the descriptive characteristics of those who converted to dementia and those who continued to suffer from QD.

\section{Statistical analyses}

Univariate Mann-Whitney $U$ and $\chi^{2}$ statistics were used to compare groups. Prediction of outcome was evaluated using Cox regression proportional hazards analysis. Either variables were used as continuous covariates, or the neuropsychological variables were recoded categorically according to whether patients scored above or below the 5 th centile cut off for age adjusted means. With the exception of the HVLT learning index these means were taken from published normative data. 
Table 2 Causes of dementia and questionable dementia

\begin{tabular}{lll}
\hline $\mathrm{n}=129$ Final diagnosis & $\begin{array}{l}\text { Developing dementia } \\
\text { Frequency (\%) }\end{array}$ & Stable QD Frequency (\%) \\
\hline Probable AD & $19(51)$ & \\
Possible AD & $2(5)$ & \\
Vascular dementia & $7(19)$ & \\
Diffuse Lewy body disease & $1(3)$ & \\
Frontal lobe dementia & $3(8)$ & 92 \\
Uncertain aetiology & $5(14)$ & $46(51)$ \\
Total & 37 & $14(16)$ \\
Cognitive impairment & & $30(33)$ \\
Cognitive impairment-vascular origin & & \\
Cognitive impairment-other causes & & \\
\hline
\end{tabular}

Table 3 Performance of groups on cognitive tests at the initial evaluation by final diagnosis

\begin{tabular}{|c|c|c|c|c|}
\hline Tests Mean (SD), range & Developing dementia & Stable QD & $\begin{array}{l}\text { Significance } \\
\text { Mann-Whitney U } \\
\text { (two tailed)* }\end{array}$ & Significance $\chi^{2 \dagger}$ \\
\hline \multicolumn{5}{|l|}{ Working memory, abstraction, problem solving } \\
\hline Digit span-forwards (max 14) & $8.2(2.4), 4-13, n=37$ & $8.4(2.6), 4-14, n=90$ & 0.691 & \\
\hline Digit span-backwards (max 14) & $6.1(2.5), 2-13, n=37$ & $6.7(2.2), 2-14, n=90$ & 0.128 & \\
\hline Similarities (max 28) & $13.4(7.1), 0-26, n=37$ & $16.0(6.3), 0-27, n=91$ & 0.046 & 0.424 \\
\hline Picture completion ( $\max 20)$ & $12.3(4.5), 2-18, n=37$ & $13.3(4.4), 3-19, n=91$ & 0.251 & 0.305 \\
\hline \multicolumn{5}{|l|}{ Episodic memory } \\
\hline Story recall-immediate ( $\max 56)$ & $11.6(9.9), 0-37, n=37$ & $18.8(10.8), 0-47, n=91$ & 0.001 & 0.000 \\
\hline Story recall-delayed $(\max 56)$ & $6.0(10.1), 0-37, n=37$ & $13.8(12.6), 0-45, n=91$ & 0.001 & 0.001 \\
\hline Percentage story retained $(\mathrm{del} / \mathrm{imm} \times 100)$ & $31.7(38.0), 0-100, n=37$ & $58.1(42.4), 0-155.6, n=91$ & 0.001 & 0.001 \\
\hline Visual recognition (max 10) & $7.8(2.4), 0-10, n=37$ & $8.8(2.2),-1-10, n=92$ & 0.015 & 0.003 \\
\hline Verbal learning-learning index (max 1.0$)$ & $0.15(0.10), 0-0.42, n=32$ & $0.23(0.16), 0-0.90, n=84$ & 0.003 & 0.146 \\
\hline HVLT total list recall (max 36) & $14.2(5.6), 3-26, n=32$ & $17.8(4.6), 7-30, n=86$ & 0.001 & 0.021 \\
\hline Verbal recognition ( $\max 12)$ & $7.3(2.7), 0-11, n=31$ & $9.6(2.2), 0-12, n=85$ & 0.001 & 0.004 \\
\hline \multicolumn{5}{|l|}{ Language and executive function } \\
\hline Frenchay Aphasia Screening Test (max 15) & $14.3(0.7), 13-15, n=35$ & $14.3(0.9), 11-15, n=89$ & 0.917 & 0.828 \\
\hline Verbal fluency & $36.6(11.5), 9-56, n=36$ & $41.1(11.1), 18-69, n=87$ & 0.044 & 0.145 \\
\hline Weigl's colour form sorting ( $\max 4)$ & $3.5(0.8), 1-4, n=35$ & $3.6(0.8), 1-4, n=92$ & 0.676 & 0.588 \\
\hline \multicolumn{5}{|l|}{ Cognitive speed } \\
\hline Digit copy-age scaled score (max 210) & $102.9(20.5), 53-151, n=37$ & $106.5(20.1), 60-155, n=86$ & 0.384 & 0.510 \\
\hline \multicolumn{5}{|l|}{ Visuospatial function } \\
\hline Cube analysis $(\max 10)$ & $9.2(1.3), 4-10, n=37$ & $9.4(1.5), 0-10, n=91$ & 0.398 & 0.896 \\
\hline
\end{tabular}

* Mann-Whitney $U$ analysis conducted to compare groups on continuous predictor variables; $\nmid \chi^{2}$ analysis conducted to compare groups on predictor variables recoded to categorical variables (above and below the 5 th centile rank).

The Learning Index was based on a similar index developed by Bucks et al ${ }^{58}$ (see footnote*). All analyses were performed with SPSS for Windows version $11.0^{59}$ using an $\alpha$ level of 0.05 .

\section{RESULTS}

There were no significant differences between the groups in premorbid IQ, years of education, dependency, ischaemic score, or depression, nor was there a significant sex difference. Those who developed dementia reported a significantly shorter mean history of cognitive impairment, had significantly lower mean MMSE scores, and were significantly older than those who did not develop dementia (see table 2). Table 2 shows the distribution of diagnoses. In those who went on to develop dementia, a diagnosis of probable or possible $\mathrm{AD}$ was

*The index quantifies the mean proportion of 12 words learned on trials 2 and 3 as a function of how much information the participant has left to learn after trials 1 and 2 . The equation for this index is

$$
\left(\frac{\text { Trial } 2-\text { Trial } 1}{12-\text { Trial } 1}+\frac{\text { Trial } 3-\text { Trial2 }}{12-\text { Trial2 }} / 2\right)
$$

Normative data were generated from a sample of healthy controls $n=37$ aged 57-69 and $n=46$ aged $70+$ and are available from the second author. made in over half the cases. Of those who continued with QD a specific aetiology was identified in less than half.

Table 3 shows mean neuropsychological test performance at the initial visit. There were significant group differences in Similarities, all the Memory measures and Verbal Fluency.

Cox regression analyses were performed with progression to dementia as the event, and time to diagnosis or survival as the time variable. Only those variables on which the two groups performed significantly differently in univariate comparisons were entered into the equations. Because of small amounts of missing data, only those cases for whom there was complete data were entered into the analyses (QD $\mathrm{n}=80, \mathrm{D} \mathrm{n}=30$ ). Three variants of the Cox regression analysis were conducted (Enter, Forwards Stepwise, and Backwards Stepwise) for both continuous and categorical predictors. This permitted comparison with the same sorts of models found in the literature as well as an exploration of the stability of the analyses. Table 4 shows the prediction results for each of the different analyses performed.

A number of the models compared favourably with published findings. However, using the neuropsychological test scores as continuous predictor variables produces problems because of colinearity of the predictor measures: that is, the tendency for test results to vary systematically with each other as a function of disease severity. This can be seen in the degree to which Models 1 to 3 differed in the variables that were shown to contribute significantly to the likelihood of 


\begin{tabular}{|c|c|c|c|c|c|c|c|}
\hline Model & Predictor type & Method & $\begin{array}{l}\text { Variables in the equation (If the variable } \\
\text { is significantly associated with the } \\
\text { model then it is a useful predictor of } \\
\text { QD/D status at follow up. Significance is } \\
\text { indicated by tor } ¥ \text { ). }\end{array}$ & Sensitivity (\%) & Specificity (\%) & PPV (\%) & NPV (\%) \\
\hline \multicolumn{8}{|c|}{ Neuropsychological test scores as continuous predictor variables } \\
\hline 1 & Con & ENT & $\begin{array}{l}\text { Age, Startmem, MMSE, Simil, Recimm, } \\
\text { Recdel, Perrec, Visrec, HVLT, Learnind, } \\
\text { Verbrec (OR 0.76, CI } 0.63 \text { to } 0.93 \ddagger \text { ), } \\
\text { Verbflu (OR } 0.93, \mathrm{Cl} 0.88 \text { to } 0.98 \dagger \text { ) }\end{array}$ & 64.4 & 76.7 & 87.0 & 46.9 \\
\hline 2 & Con & FSW & $\begin{array}{l}\text { MMSE (OR } 0.86, \mathrm{Cl} 0.75 \text { to } 0.99 \ddagger \text { ), } \\
\text { HVLT (OR } 0.90, \mathrm{Cl} 0.83 \text { to } 0.98 \dagger \text { ) }\end{array}$ & 60.3 & 66.7 & 81.5 & 40.8 \\
\hline 3 & Con & BSW & $\begin{array}{l}\text { Age (OR } 1.08, \mathrm{Cl} 1.03 \text { to } 1.13 \ddagger) \text {. Visrec, } \\
\text { Verbrec }(0.81, \mathrm{Cl} 0.70 \text { to } 0.93 \ddagger) \text {, Verbflu } \\
\text { (OR } 0.93, \mathrm{Cl} 0.89 \text { to } 0.96 \ddagger \text { ) }\end{array}$ & 53.4 & 83.8 & 88.6 & 42.4 \\
\hline \multicolumn{8}{|c|}{ Neuropsychological test scores as categorical predictor variables (cut at 5 th centile) } \\
\hline 4 & Cat & ENT & $\begin{array}{l}\text { Age (OR 1.08, Cl } 1.03 \text { to } 1.14 \ddagger \text { ), } \\
\text { Startmem, MMSE, Recimm, Recdel, } \\
\text { Perrec, Visrec, HVLT (OR 5.57, Cl } 1.70 \text { to } \\
\text { 18.25) } \ddagger \text {, Verbrec }\end{array}$ & 58.9 & 70.0 & 82.7 & 41.2 \\
\hline 5 & Cat & FSW & $\begin{array}{l}\text { Age (OR } 1.09, \mathrm{Cl} 1.04 \text { to } 1.14 \ddagger \text { ), HVLT } \\
\text { (OR } 5.32, \mathrm{Cl} 2.08 \text { to } 13.59 \ddagger \text { ) }\end{array}$ & 57.5 & 70.0 & 82.2 & 40.4 \\
\hline 6 & Cat & BSW & $\begin{array}{l}\text { Age (OR } 1.09, \mathrm{Cl} 1.04 \text { to } 1.14 \ddagger) \text {, HVLT } \\
\text { (OR } 5.32, \mathrm{Cl} 2.08 \text { to } 13.69 \ddagger \text { ) }\end{array}$ & 57.5 & 70.0 & 82.2 & 40.4 \\
\hline
\end{tabular}

Con, continuous variables; Cat, categorical variables; ENT, all variables entered into model; FSW, forward stepwise; BSW, backward stepwise; Age, Age at initial visit; Startmem, history of cognitive impairment (months); Simil, similarities; Recimm, immediate story recall; Recdel, delayed story recall; Perrec, percentage story recalled on delay; Visrec, visual recognition; HVLT, HVLT total recalled; Learnind, HVLT Learning index; Verbrec, verbal recognition; Verbflu, verbal fluency; $\dagger \mathrm{p}<0.05 ; \ddagger \mathrm{p}<0.01 ; \mathrm{PPV}$, positive predictive value; NPV, negative predictive value; OR, odds ratio; Cl, $95 \%$ confidence intervals.

converting to dementia. In Model 1 , all variables were forced into the equation together. Only two were found to be potentially significant explanatory variables: Verbal Recognition and Verbal Fluency. In Model 2, a forwards stepwise procedure resulted in two different variables, HVLT Total List Recall and MMSE being left in the equation. In Model 3, using continuous covariates, a backwards stepwise procedure resulted in four variables being left in the equation, two of which were the same as the significant explanatory variables in Model 1 , and none of which was the same as in Model 2. These were Age, Visual Recognition, Verbal Recognition, and Verbal Fluency. In the models that used categorical covariates there was consistency in the variables that were identified as significant predictors (Models 4-6) methods. In all three the significant covariates were Age and HVLT Total List Recall.

\section{DISCUSSION}

As in previous studies, ${ }^{814-17243536}$ a number of neuropsychological parameters seem to offer potential to distinguish between those who will and those who will not go on to dement. However, despite significant group differences in these measures, many did not prove to be consistently significant predictors of conversion to dementia. For example, despite a significant difference in mean MMSE score, this was not consistently a significant predictor of final diagnosis of dementia, indeed it was only a significant predictor in one model. This finding reflects the generally poor status of the MMSE as a significant predictor noted in other studies. ${ }^{123860}$

As has previously been found, there were significant differences between the QD and D groups on univariate analysis of all memory tests. ${ }^{7618233060}$ However, the predictive power of memory test performance was less convincing. Recall performance, whether Immediate or Delayed, was not found to be significantly predictive of final diagnosis, although, Verbal Recognition was found to be a significant predictor in Models 1 and 2. Other neuropsychological test variables that appeared as significant predictors in some models were Verbal Fluency (Models 1 and 3) and Visual Recognition (Model 3).

In all analyses using categorical scores (Models 4-6) only low Total List Recall performance was significantly associated with increased risk of converting to dementia. Otherwise, only increasing Age was consistently found to be moderately positively associated with increased risk of converting to dementia: a finding consistent with a number of other studies. $^{183861}$

By comparison with the Devanand results, ${ }^{2}$ a smaller proportion of our sample converted to dementia $(27.4 \%$ compared with $41.3 \%$ ). Although this may relate to the slightly shorter mean interval of follow up (25 months compared with 30 months) between the studies, there was no significant difference between our groups in the length of follow up to diagnosis or survival making this explanation unlikely. There was also a smaller proportion of subjects with diagnoses of probable or possible AD; in our sample 56.6\%, in Devanand et al $87.1 \%$.

Despite this difference in base rates of conversion, in terms of predictive accuracy, these results seem to replicate Devanand et al. Indeed, the sensitivity, specificity, positive and negative predictive values appeared quite good. Sensitivity values ranged from $53.4 \%$ to $64.4 \%$. Specificity values ranged from $66.7 \%$ to $83.3 \%$. Positive predictive values (PPV) were equally good, although the best was associated with only modest sensitivity (Model 3) and should, therefore, be discounted. Good sensitivity is often gained at the expense of poor specificity, with the same trade off occurring for PPV and negative predictive values (NPV). For example, the best PPV (Model 1: $87.0 \%$ ) was associated with poor NPV $(46.9 \%)$. Thus, for every two people who were predicted to continue with QD, this would be incorrect for one of them. In addition, only two thirds of the people who actually did convert to a diagnosis of dementia were correctly identified (sensitivity $64.4 \%$ ) and one in four of those who did not were misidentified (specificity $76.7 \%$ ). Thus, a technique that at first sight looks promising, is really rather less than satisfying.

Review of the literature reveals a number of explanations for this general difficulty with predictive studies. These include issues of test sensitivity, ${ }^{16}$ as well as the problem that many of the tests are highly intercorrelated. This colinearity between independent variables is one of the primary reasons for poor regression models. Unfortunately, few studies confront this issue. For example, despite reporting a failure to find significant associations attributable to colinearity in their 
predictor variables Devanand et $a l^{2}$ went on to conduct a discriminant function analysis. Discriminant function uses another type of regression model that is no less susceptible to the effects of colinearity than their original analysis. Many other studies simply force all variables into their regression models (Enter method) rather than allowing them to be placed into or out of the final equation according to a statistical criterion as in a stepwise model. With highly intercorrelated data, in a stepwise model what ends up in the equation will therefore depend on the order with which the variables were put into or taken out of the equation. This is demonstrated clearly by the instability shown between Models 1 to 3.

Some researchers have sought to resolve this correlation problem by conducting principal components analysis (PCA) to reduce their dataset to a smaller number of uncorrelated components. $^{24252862}$ Fabrigoule and colleagues ${ }^{2425} 28$ isolated a component that they interpreted as reflecting a disturbance of control processes. Indeed, a number of researchers have argued that studies should be focusing on attentional control processes in their search for a specific marker of incipient dementia. ${ }^{242562}$ Findings regarding the extremely specific nature of the central executive deficits found in mild $A D$ patients, particularly their marked difficulty with dual task performance ${ }^{6364}$ would tend to support this view. However, reported inconsistency regarding the components identified by PCA, ${ }^{28}{ }^{62}$ and the difficulty of applying PCA analysis to routine clinical data make such approaches currently unsuitable.

An additional problem with these types of studies is that many of the groups have different mean years of education or predicted premorbid IQ scores. A number of studies have controlled for this difference by regressing out years of education or IQ before analysing the predictive power of the test scores. ${ }^{78253234}$ Unfortunately, analysis of covariance is often not an appropriate method for providing statistical control over differences between groups in neuropsychological research, as it can remove the variance of interest that is associated with age or education factors. ${ }^{65}$ One final problem with these types of studies is that while some exclude people with depression, others do not. However, evidence relating to the additional effect of depression on risk of developing dementia is equivocal. ${ }^{61}{ }^{66}$ Moreover, in this study, mean IQ, years of education and mean number of depressive symptoms did not differ between the two groups.

It could be argued that any study predicting conversion from an outpatient population, such as that taken from a memory clinic will be problematic given the lack of generalisability to the general population of older adults. However, a large number of studies using both community and clinic based samples have failed consistently to identify a class or class of neuropsychological measures that produce satisfactory prediction rates. Thus, the issue seems less to be one of generalisability of the findings and more of generalisability of the method; which we feel has yet to be established.

Perhaps, it is currently ambitious to try to predict long term outcome from assessment at a single time point. Indeed, a number of studies have attempted to evaluate the predictive power of change scores. ${ }^{3362}{ }^{67}$ While some studies have found evidence of significant changes in test performance up to five years before diagnosis, ${ }^{67}{ }^{68}$ others have shown marked changes in test performance only shortly before the diagnosis is made. ${ }^{2633}$ Furthermore, at least one set of researchers have questioned the validity of any predictive studies. ${ }^{62}$

A range of alternative avenues for predicting conversion to dementia are currently being explored in the literature (see Almkvist and Winblad ${ }^{69}$ for a review). These include volumetric analyses of medial temporal lobe and hippocampal structures, ${ }^{20} 70-75$ functional neuroimaging analyses of blood flow, ${ }^{5}$ or of cortical glucose metabolism, ${ }^{37}$ genetic risk factors (for example, apoE4, ) $^{15} 35$ 36 76-78 biological markers in cerebrospinal fluid, ${ }^{1}$ and nerve growth factor. ${ }^{32}$ Indeed, Collie and
Maruff ${ }^{5}$ and Reischies and Hellweg ${ }^{78}$ recommended a convergent approach, combining measures (see for example, Albert $^{74}$ and Daly et $a l^{36}$ ). While a convergent approach may improve predictive validity, it makes predictions of this type even further beyond the reach of the average geriatric outpatient service. In addition, it does not avoid the serious difficulties identified with determining what is normal for cognitive or neuroanatomical measures for any particular age group.

While it is tempting to seek a combination of neuropsychological and clinical measures that can predict the development of dementia, analysis of our clinical data suggests that it would be more fruitful to expend our energies on searching for a new, specific and unique cognitive, biological or anatomical marker, than to pursue these types of predictive models. Unfortunately, statistical significance does not, as yet, offer clinical utility.

\section{ACKNOWLEDGEMENTS}

We would like to thank Anthony Hughes and Lucie Byrne for statistical and methodological advice, and Maggie Agg for database support. Romola Bucks was supported by the charity, Bristol Research into Alzheimer's and Care of the Elderly (BRACE). The Chinese Government sponsored Professor Jinzhou Tian. We are grateful to the reviewers for their helpful comments on an earlier version of this article.

\section{Authors' affiliations}

J Tian, Department of Care of the Elderly, Beijing University of Chinese Medicine, Dongzhimen Hospital, Beijing, China

R S Bucks, Department of Psychology, University of Southampton, Southampton, UK

J Haworth, G Wilcock, Department of Care of the Elderly, University of Bristol, Frenchay Hospital, Bristol, UK

Competing interests: none declared.

\section{REFERENCES}

1 Howieson DB, Dame A, Camicioli R, et al. Cognitive markers preceding Alzheimer's dementia in the healthy oldest old. J Am Geriatr Soc 1997:45:584-9.

2 Devanand DP, Folz M, Gorlyn M, et al. Questionable dementia: clinical course and predictors of outcome. J Am Geriatr Soc 2000;45:321-8.

3 Celsis P. Age-related cognitive decline, mild cognitive impairment or preclinical Alzheimer's disease? Ann Med 2000;32:6-14.

4 Morris JC, Storandt M, Miller JP, et al. Mild cognitive impairment represents early-stage Alzheimer disease. Arch Neurol 2002; 58:397-405

5 Collie A, Maruff P. The neuropsychology of preclinical Alzheimer's disease and mild cognitive impairment. Neurosci Biobehav Rev 2000;24:365-74.

6 Herlitz A, Small BJ, Fratiglioni L, et al. Detection of mild dementia in community surveys. Is it possible to increase the accuracy of our diagnostic instruments? Arch Neurol 1997;54:319-24

7 Jacobs DM, Sano M, Dooneief G, et al. Neuropsychological detection and characterization of preclinical Alzheimer's disease. Neurology 1995;45:957-62.

8 Linn RT, Wolf PA, Bachman DL, et al. The preclinical phase of probable Alzheimer's disease: a 13 year prospective study of the Framingham cohort. Arch Neurol 1995;52:485-90.

9 Ritchie K, Kildea D. Is senile dementia " age-related" or "aging-related"? Evidence from meta-analysis of dementia prevalence in the oldest old. Lancet 1995;346:931-4.

10 Graham JE, Rockwood K, Beattie BL, et al. Prevalence and severity of cognitive impairment with and without dementia in an elderly population. Lancet 1997:349:1793-6.

11 Bowen J, Teri L, Kukull W, et al. Progression to dementia in patients with isolated memory loss. Lancet 1997;349:763-5.

12 Petersen RC, Smith GE, Waring SC, et al. Mild cognitive impairment: clinical characterization and outcome. Arch Neurol 1999:56:303-8.

13 Brayne C, Best N, Muir M, et al. Five-year incidence and prediction of dementia and cognitive decline in a population sample of women aged 70-79 at baseline. Int J Geriatr Psychiatr 1997;12:1107-18.

14 Mayeux R, Stern Y, Ottman R, et al. The apolipoprotein E4 allele in patients with Alzheimer's disease and related disorders. Ann Neurol 1993;34:752-4.

15 Bondi M, Salmon D, Galasko D, et al. Neuropsychological function and apolipoprotein E genotype in the preclinical detection of Alzheimer's disease. Psychol Aging 1999;14:295-303.

16 Flicker C, Ferris S, Reisberg B. A two-year longitudinal study of cognitive function in normal aging and Alzheimer's disease. J Geriatr Psychiatr Neurol 1993;6:84-96. 
17 Hanninen T, Hallikainen M, Koivisto K, et al. A follow-up study of age-associated memory impairment: neuropsychological predictors of dementia. J Am Geriatr Soc 1995;43:1007-15.

18 Elias MF, Beiser A, Wolf PA, et al. The preclinical phase of Alzheime disease: a 22-year prospective study of the Framingham Cohort. Arch Neurol 2000;57:808-13

19 Masur DM, Sliwinski M, Lipton RB, et al. Neuropsychological prediction of dementia and the absence of dementia in healthy elderly persons. Neurology 1994;44:1427-32.

20 Fox NC, Warrington EK, Freeborough PA, et al. Presymptomatic hippocampal atrophy in Alzheimer's disease. A longitudinal MRI study. Brain 1996; 119:2001-7

21 Grober E, Lipton RB, Hall C, et al. Memory impairment on free and cued selective reminding predicts dementia. Neurology 2000;54:827-32.

22 Grober E, Kawas C. Learning and retention in preclinical and early Alzheimer's disease. Psychol Aging 1997;12:183-8.

23 Rubin EH, Storandts M, Miller JP, et al. Influence of age on clinical and psychometric assessment of subjects with very mild or mild dementia of the Alzheimer type. Arch Neurol 1993;50:380-3.

24 Dartigues JF, Commenges D, Letteneur L, et al. Cognitive predictors of dementia in elderly community residents. Neuroepidemiology 1997; 16:29-39

25 Fabrigoule C, Rouch I, Taberly A, et al. Cognitive process in preclinical phase of dementia. Brain 1998;121:135-41.

26 Small BJ, Herlitz A, Fratiglioni L, et al. Cognitive predictors of incident Alzheimer's disease: A preospective longitudinal study. Neuropsychol 1997; 11:413-20.

27 Nielsen H, Lolk A, Andersen K, et al. Characteristics of elderly who develop Alzheimer's disease during the next two years-a neuropsychological study using CAMCOG. The Odense Study. Int J Geriatr Psychiatry 1999; 14:957-63.

28 Amieva H, Rouch-Leroyer I, Fabrigoule C, et al. Deterioration of controlled processes in the preclinical phase of dementia: a confirmatory analysis. Dement Geriatr Cogn Discord 2000;11:46-52.

29 Morris J, McKeel D Jr, Storandt M, et al. Very mild Alzheimer's disease: informant-based clinical, psychometric, and pathologic distinction from normal ageing. Neurology 1991;41:469-78.

30 Robinson-Whelen S, Storandt $M$. Immediate and delayed prose recall among normal and demented adults. Arch Neurol 1992:49:32-4.

31 Welsh K, Butters N, Hughes J, et al. Detection of abnormal memory decline in mild cases of Alzheimer's disease using CERAD neuropsychological measures. Arch Neurol 1991;48:278-81.

32 Small BJ, Viitanen M, Backman L. Mini-Mental State Examination item scores as predictors of Alzheimer's disease: incidence data from the Kungsholmen Project, Stockholm. J Gerontol A Biol 1997;52:M299_ 304.

33 Small BJ, Fratiglioni L, Viitanen M, et al. The course of cognitive impairment in preclinical Alzheimer disease: three- and 6-year follow-up of a population-based sample. Arch Neurol 2000;57:839-44.

34 Kluger A, Ferris SH, Golomb J, et al. Neuropsychological prediction of decline to dementia in nondemented elderly. J Geriatr Psychiatry Neurol 1999;12:168-79.

35 Tierney MC, Szalai JP, Snow WG, et al. Prediction of probable Alzheimer's disease in memory-impaired patients: a prospective longitudinal study. Neurology 1996;46:661-5.

36 Daly E, Zaitchik D, Copeland $M$, et al. Predicting conversion to Alzheimer disease using standardized clinical information. Arch Neurol 2000;57:675-80.

37 Visser PJ, Verhey FR, Ponds RW, et al. Course of objective memory impairment in non-demented subjects attending a memory clinic and predictors of outcome. Int J Geriatr Psychiatry 2000;15:363-72.

38 Hogan, Elby. Predicting who will develop dementia in a cohort of Canadian seniors. Can J Neurol Sci 2000;27:18-24.

39 Crook T, Bartus RT, Ferris SH, et al. Age-associated memory impairment: proposed diagnostic criteria and measures of clinical change-Report of a National Institute of Mental Health Work Group Dev Neuropsychol 1986;2:261-76.

40 Ritchie K, Touchon J. Mild Cognitive Impairment: conceptual basis and current nosological status. Lancet 2000;355:225-8.

41 Collie A, Maruff P. An analysis of systems of classifying mild cognitive impairment in older people. Aust N Z J Psychiatry 2002;36:133-40.

42 Alexopoulos GS, Abrams RC, Young RC, et al. Cornell scale for depression in dementia. Biol Psychiatry 1988;23:271-84.

43 Gilleard CJ, Pattie AM. The Stockton Geriatric Rating Scale: a shortened version with British normative data. Br J Psychiatry 1977;14:90-4.

44 Hachinski VC, Lassen NA, Marshall J. Multi-infarct dementia: A cause of mental deterioration in the elderly. Lancet 1974;ii:207.

45 O'Neill D, Gerrard J, Surmon D, et al. Variability in scoring the Hachinski Ischaemic Score. Age Ageing 1995;24:242-6.

46 Bucks RS, Loewenstein DA. Neuropsychological assessment. In: Wilcock GK, Bucks RS, Rockwood K, eds. Diagnosis and management of dementia: a manual for memory disorders teams. Oxford: Oxford University Press, 1999.
47 Wechsler D. Wechsler Adult Intelligence Scale-Revised. San Antonio: Psychological Corporation, 1981

48 Coughlan AK, Hollows SE. The Adult Memory and Information Processing Battery (AMIPB). Leeds: St James's University Hospital, 1985.

49 Brandt J. The Hopkins Verbal Learning Test: development of a new memory test with six equivalent forms. Clin Neuropsychol 1991;5:125-42.

50 Golding E. The Middlesex Elderly Assessment of Mental State. Bury St Edmunds: Thames Valley Test Company, 1989.

51 Enderby P, Wood V, Wade D. Frenchay Aphasia Screening Test Manual. Windsor: NFER-Nelson, 1987.

52 Lezak MD. Neurospychological assessment. 3rd edn. New York: Oxford University Press, 1995

53 Byrne LMT, Bucks RS, Cuerden JM. Validation of a new scoring system for the Weigl Color Form Sorting test in a memory disorders clinic sample. J Clin Exp Neuropsychol 1998;20:286-92.

54 Warrington EK, James M. The Visual Object Space Perception Battery. Bury St Edmunds: Thames Valley Test Company, 1991

55 Kendrick DC. Kendrick cognitive tests for the elderly. Windsor: NFER-Nelson, 1985

56 American Psychiatric Association. Diagnostic and statistical manual of mental disorders-revised IV edn. (DSM- IV-R, APA). Washington, DC American Psychiatric Press, 1994

57 McKhann G, Drachman D, Folstein M et al. Clinical diagnosis of Alzheimer's disease: Report of the NINCDS-ADRDA work group under the auspices of Department of Health and Human Services Task Force on Alzheimer's disease. Neurology 1984;34:939-44.

58 Bucks RS, Willison JR, Byrne LMTB. The Location Learning Test. Bury St Edmunds: Thames Valley Test Company, 2000.

59 SPSS. SPSS 11.0 for Windows. Chicago, IL: SPSS, 2001

60 Galasko D, Corey-Bloom J, Thal LY. Monitoring progression in Alzheimer's disease. J Am Geriatr Soc 1991;39:932-41.

61 van Reekum R, Simard M, Cohen T. The prediction and prevention of Alzheimer's disease-towards a research agenda. J Psychiatr Neurosci 1999:24:413-30

62 Rubin EH, Storandt M, Miller JP, et al. A prospective study of cognitive function and onset of dementia in cognitively healthy elders. Arch Neurol 1998;55:395-401.

63 Perry RJ, Hodges JR. Attention and executive deficits in Alzheimer's disease: a critical review. Brain 1999;122:383-404

64 Baddeley AD, Baddeley HA, Bucks RS, et al. Attentional control in Alzheimer's disease. Brain 2001;124:1492-508.

65 Adams KM, Brown GG, Grant I. Analysis of covariance as a remedy for demographic mismatch of research subject groups: Some sobering simulations. J Clin Exp Neuropsychol 1985;7:445-62.

66 Visser PJ, Verhey FRJ, Ponds RWHM, et al. Distinction between preclinical Alzheimer's disease and depression. J Am Geriatr Soc 2000;48:479-84

67 Hall CB, Lipton RB, Sliwinski $M$, et al. A change point model for estimating the onset of cognitive decline in preclinical Alzheimer's disease. Stat Med 2000; 19:1555-66.

68 Fowler KS, Saling MM, Conway EL, et al. Computerized neuropsychological tests in the early detection of dementia: prospective findings. J Int Neuropsychol Soc 1997;3:139-46.

69 Almkvist O, Winblad B. Early diagnosis of Alzheimer dementia based on clinical and biological factors. Eur Arch Psychiatr Clin Neurosc 1999;249:III/3-9.

70 Convit A, de Asis J, de Leon M, et al. Atrophy of the medial occipitotemporal, inferior, and middle temporal gyri in non-demented elderly predict decline to Alzheimer's disease. Neurobiol Aging 2000;21:19-26.

71 Kaye JA, Swihart T, Howieson D, et al. Volume loss of the hippocampus and temporal lobe in healthy elderly persons destined to develop dementia. Neurology 1997:48:1297-304.

72 Jack CRJ, Petersen RC, Xu YC, et al. Prediction of AD with MRI-based hippocampal volume in mild cognitive impairment. Neurology 1999;52:1397-403.

73 Killiany RJ, Gomez-lsla T, Moss M, et al. Use of structural magnetic resonance imaging to predict who will get Alzheimer's disease. Ann Neurol 2000;47:430-9.

74 Albert MS. Preclinical predictors of Alzheimer's disease. Brain Cog 1997;35:284-426

75 Wolf H, Grunwald M, Kruggel F, et al. Hippocampal volume discriminates between normal cognition; questionable dementia and mild dementia in the elderly. Neurobiol Aging 2001;22:177-86

76 Ritchie K, DupuyA-M. The current status of APO E4 as a risk factor for Alzheimer's Disease: an epidemiological perspective. Int J Geriatr Psychiatry 1999;14:695-700.

77 Skoog I. Detection of preclinical Alzheimer's disease. N Engl J Med 2000;343:502-3

78 Reischies FM, Hellweg R. Prediction of deterioration in mild cognitive disorder in old age-neuropsychological and neurochemical parameters of dementia diseases. Comp Psychiatry 2000;41:166-75. 